\title{
Comparing Memory Skill Maintenance Across the Life Span: Preservation in Adults, Increase in Children
}

\author{
Yvonne Brehmer \\ Saarland University, Max Planck Institute for Human \\ Development, and Karolinska Institute
}

\author{
Shu-Chen Li \\ Max Planck Institute for Human Development
}
Timo von Oertzen, Viktor Müller, and Ulman Lindenberger

Saarland University and Max Planck Institute for Human Development

\begin{abstract}
The authors examined life-span differences in the maintenance of skilled episodic memory performance by assessing 100 individuals $(10-11,12-13,21-26$, and 66-79 years old) 11 months after termination of an intensive multisession mnemonic training program (Y. Brehmer, S.-C. Li, V. Müller, T. von Oertzen, \& U. Lindenberger, 2007). Skill maintenance was tested in 2 follow-up sessions, the first without and the second with mnemonic reinstruction. Younger and older adults' average performance levels were stable across time. In contrast, both younger and older children's memory performance improved beyond originally attained levels. Older adults' performance improved from the first to the second follow-up session, presumably profiting from instruction-induced skill reactivation. Results suggest that (a) skill maintenance is largely intact in healthy older adults, (b) older adults need environmental support to fully reactivate their former skill levels (cf. F. I. M. Craik, 1983), and (c) children adapt a skill learned 11 months ago to their increasing cognitive capabilities.
\end{abstract}

Keywords: plasticity, episodic memory, life-span development, skill maintenance, cognitive intervention

Plasticity, or the tendency of organisms to alter their behavior in response to environmental challenges, is present throughout ontogeny (Baltes, Lindenberger, \& Staudinger, 2006; Bialystok \&

Yvonne Brehmer, School of Psychology, Saarland University, Saarbrücken, Germany; Center for Lifespan Psychology, Max Planck Institute for Human Development, Berlin, Germany; and Aging Research Center, Karolinska Institute, Stockholm, Sweden. Shu-Chen Li, Center for Lifespan Psychology, Max Planck Institute for Human Development. Benjamin Straube and Gundula Stoll, School of Psychology, Saarland University. Timo von Oertzen, Viktor Müller, and Ulman Lindenberger, School of Psychology, Saarland University; and Center for Lifespan Psychology, Max Planck Institute for Human Development.

This study was carried out in the context of the German Research Foundation Grant DFG FOR 448 Binding: Functional Architecture, Neuronal Correlates, and Ontogeny and was conducted in partial fulfillment of the requirements for the doctoral dissertation of Yvonne Brehmer. The dissertation work was also supported by a stipend from the International Max Planck Research School for The Life Course: Evolutionary and Ontogenetic Dynamics (LIFE).

The authors would like to thank Paul B. Baltes, Lars Bäckman, Christopher Hertzog, Yee Lee Shing, Anne-Cécile Treese, and Hubert Zimmer who provided helpful comments on earlier versions of this article. We would also like to thank Michael Schellenbach for technical assistance.

Correspondence concerning this article should be addressed to Yvonne Brehmer, Aging Research Center, Karolinska Institute, Gävlegatan 16, Stockholm S-11330, Sweden; or to Shu-Chen Li or Ulman Lindenberger, Center for Lifespan Psychology, Max Planck Institute for Human Development, Lentzeallee 94, Berlin 14195, Germany. E-mail: yvonne.brehmer@ki.se, shuchen@mpib-berlin.mpg.de, or lindenberger@mpib-berlin.mpg.de
Craik, 2006; Li, 2003). In the domain of cognitive functioning many studies have shown that individuals' performance can, in principle, be influenced in a positive direction through intervention and training; however, the scope and magnitude of plasticity vary with age. Conceptually, Baltes and colleagues (Baltes, 1987; Kliegl \& Baltes, 1987) distinguished among three levels of cognitive functioning: baseline performance, baseline plasticity (baseline reserve capacity), and developmental plasticity (developmental reserve capacity). While baseline performance relates to the initial performance level of individuals, baseline plasticity indicates the extended performance range of individuals after interventions that allowed them to make use of additional resources (e.g., performance-enhancing strategies or cues). Developmental plasticity refers to the further extended performance range of individuals after task conditions have been optimized to allow them to fully activate and possibly expand their cognitive functioning (e.g., extensive practice in strategy or cue utilization). Experimentally, the levels and limits of individuals' cognitive plasticity, in particular in episodic memory, have mostly been investigated in aging research with testing-the-limits procedures (Baltes, 1987; Kliegl \& Baltes, 1987; Kliegl, Smith, \& Baltes, 1990) and gradually increased task difficulty levels (adaptive training). It has been shown that cognitively healthy older adults are able to acquire and utilize memory strategies (e.g., mnemonic techniques) up to their $80 \mathrm{~s}$ and that they improve their memory performance through this form of contextual support, though the amount of plasticity is greatly reduced relative to that of young adults (Singer, Lindenberger, \& Baltes, 2003). 
According to life-span theories, plasticity is a fundamental aspect of lifelong development. Its investigation permits discovery of developmental trajectories of cognitive processes over the life span and of how they are related to each other at different periods of ontogeny (Baltes, Reuter-Lorenz, \& Rösler, 2006; Bialystok \& Craik, 2006). However, in most functional domains, including episodic memory, plasticity in old age has rarely been directly compared with plasticity in children.

In an earlier study (Brehmer et al., 2007), we investigated memory plasticity in a life-span sample of 108 participants who were 9-10, 11-12, 20-25, and 65-78 years old. All individuals participated in a multisession memory training that included mnemonic imagery instructions and testing-the-limits procedures to minimize the influence of age differences in pre-experimental knowledge on performance and to approximate individual differences in upper limits of skilled episodic memory performance. Participants learned and practiced an imagery-based mnemonic technique to encode and retrieve words by location cues. Two main findings were obtained (see Figure 1). First, individuals in all age groups improved episodic memory performance through mnemonic instruction and practice, reflecting the presence of memory plasticity in most periods of life. When the improvements are expressed in standard deviation $(S D)$ units of pretest performance, average performance gains exceeded 1.5 $S D$ units in all four age groups. Second, older adults profited considerably less from practicing the mnemonic technique than did children and were eventually surpassed by children at posttest.

The results of the Brehmer et al. (2007) study are in line with life-span theories (Baltes, Reuter-Lorenz, et al., 2006) that propose children possess higher levels of plasticity than older adults. In addition to tracing age-related similarities and differences in the magnitude and relative amount of plasticity following cognitive intervention, examination of whether the levels of skilled memory performances acquired previously can be maintained over a longer time period could help researchers to connect microgenetic variability with long-term changes and potentially also with ontogenetic changes, consequently deepening scientific understanding of maturation, senescence-related changes, and learning across the life span. In the present study, we extended the findings of Brehmer et al. (2007) by exploring life-span differences in the degree to which skilled episodic memory performance is maintained over time. For this purpose, we reassessed the participants of the original study 11 months after the end of the first memory training study.

\section{Age Differences in Maintenance of Memory Skill}

We must piece together the available empirical evidence on life-span differences in memory skill maintenance from studies that covered different age ranges and used different procedures. We first discuss the available literature on children and then turn to studies on plasticity from early adulthood to old age.

\section{Childhood}

Developmental research with children has tended to emphasize the importance of meta-cognitive skills and higher order cognitive processes; less attention has been paid to basic mechanisms of learning and memory. However, recent work has addressed the dynamic interplay between knowledge and basic processing mechanisms (e.g., Cowan, 1997; Nelson, 2002; Nelson, Thomas, \& de Haan, 2006; Siegler, 2000). Nevertheless, with some exceptions such as working memory training in children with attentiondeficit/hyperactivity disorder (e.g., Klingberg et al., 2005), training studies on memory plasticity and its long-term maintenance are sparse. Instead, memory-training studies with children typically examine maintenance of training effects over short intervals and up to a few months (e.g., Bjorklund, Ornstein, \& Haig, 1977;

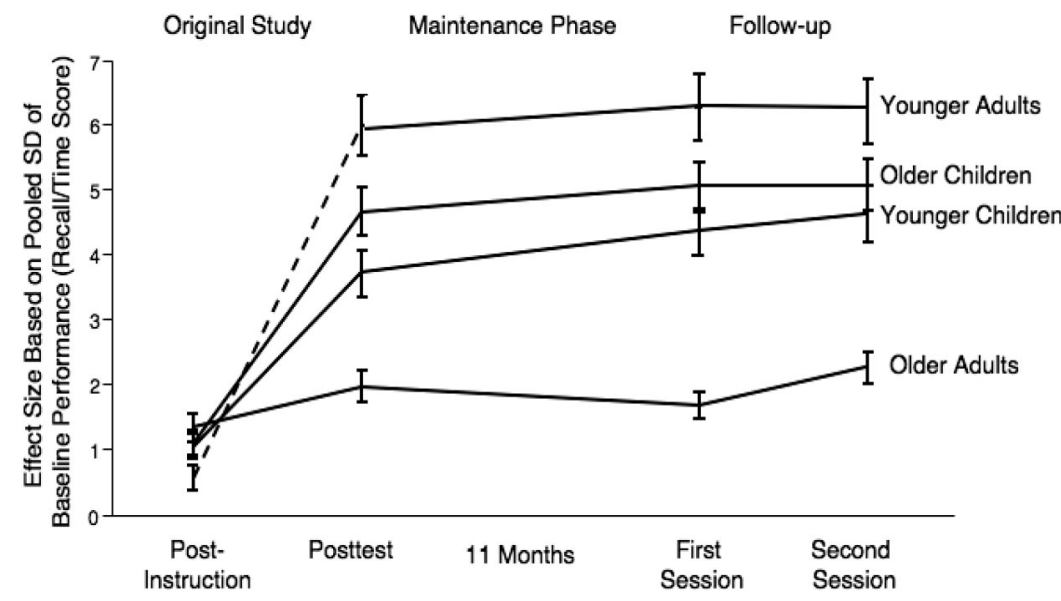

Figure 1. Memory plasticity across the life span: Overview of results from the original study by Brehmer et al. (2007) and the present follow-up study. The left part of the figure summarizes the results of the original study by Brehmer et al. (2007). The right part of the figure summarizes the results of the present study that was conducted after an 11-month time interval. Levels of memory performance refer to the number of words recalled over log encoding times (recall/time scores) and are expressed in pooled pretest standard deviation units. For young adults, the postinstruction scores of the original session cannot be interpreted because of ceiling effects; all other scores are interpretable. Error bars indicate standard errors of the mean. 
Ferrara, Brown, \& Campione, 1986). Also, most studies investigated mnemonic strategies of relatively low complexity such as rote rehearsal (Kennedy \& Miller, 1976) or simple categorization (Bjorklund, Schneider, Cassel, \& Ashley, 1994; Schneider \& Sodian, 1988), predominantly in younger children (e.g., preschoolers or first and second graders), without extensive training (e.g., Cox, 1994; Kurtz \& Borkowski, 1984). A typical result from these studies is that older children are more likely to adhere to the instructed strategy and maintain postintervention levels of memory performance than younger children (e.g., Bjorklund, Miller, Coyle, \& Slawinski, 1977; Lange \& Pierce, 1992).

Episodic memory development and maintenance of memory skills have been discussed in terms of efficiency and deficiency concepts (for a review, see Bjorklund et al., 1997). Age-graded improvements in episodic memory have been linked to basic cognitive mechanisms, such as working memory capacity (e.g., Diamond, Briand, Fossella, \& Gehlbach, 2004; Gathercole, Oickering, Ambridge, \& Wearing, 2004), executive functions (e.g., Davidson, Amso, Anderson, \& Diamond, 2006), and processing speed (e.g., Fry \& Hale, 2000), and to higher order cognitive abilities such as meta-memory (e.g., Schneider, 2000) and strategy use (e.g., Siegler, 2002). Various aspects of maturational changes in the prefrontal cortex, such as metabolic activity and myelination (e.g., Chugani, 1994), neurochemistry (e.g., Diamond et al., 2004; Nelson et al., 2000), and other anatomical changes (e.g., Sowell et al., 2003) have been related to episodic memory development in general and to skill maintenance in particular (e.g., Klingberg, Forssberg, \& Westerberg, 2002).

Though past research on memory plasticity in childhood is rather heterogeneous in emphasis and scope, some recurring dimensions can be identified. These include children's age, maintenance duration, intensity of memory training, complexity of the memory skill, and the extent of children's meta-cognitive knowledge. Furthermore, there is evidence suggesting that prefrontal cortex maturation is closely linked to episodic memory development in middle and late childhood, including various manifestations of memory plasticity.

\section{Adulthood and Old Age}

Adult age differences in plasticity of episodic memory performance have been examined in training studies that combine mnemonic instructions with several sessions of training and practice (Anschutz, Camp, Markley, \& Kramer, 1987; Ball et al., 2002; Brooks, Friedman, Pearman, Gray, \& Yesavage, 1999; Cavallini, Pagnin, \& Vecchi, 2003; Kliegl, Smith, \& Baltes, 1989, 1990; Lindenberger, Kliegl, \& Baltes, 1992; Stigsdotter \& Bäckman, 1989; Yesavage \& Rose, 1984). A general conclusion is that episodic memory plasticity continues to be present in old age but is greatly reduced in magnitude (e.g., Baltes \& Kliegl, 1992; Singer et al., 2003; Verhaeghen, Marcoen, \& Goossens, 1992).

With respect to maintenance of memory skill, studies among older adults have provided a mixed picture. Some studies have reported long-term maintenance of intervention-induced memory benefits over time periods up to 5 years (Ball et al., 2002; Derwinger, Stigsdotter Neely, \& Bäckman, 2005; Stigsdotter Neely \& Bäckman, 1993a, 1993b, 1995; Willis et al., 2006), while others have reported findings suggesting a lack of skill maintenance (Anschutz et al., 1987; Sheikh, Hill, \& Yesavage, 1986). This apparent inconsistency among relevant studies probably reflects differences in stimulus materials, amount of training or practice, statistical power, and sample characteristics (see Rebok, Carlson, \& Langbaum, 2007, for review).

Recently, Nyberg (2005) proposed that aging-related reductions in memory plasticity including skill maintenance might reflect a combination of processing and production deficits. Processing deficits refer to reductions in task-relevant resources such as working memory (Mitchell, Johnson, Raye, \& D'Esposito, 2000), attention and inhibition (see McDowd \& Shaw, 2000, for review), and processing speed (e.g., Salthouse, 1996) and are presumably related to senescent changes in anatomy (e.g., Raz et al., 2005, in press), neuromodulation (e.g., Bäckman, Nyberg, Lindenberger, Li, \& Farde, 2006), and metabolism (Volkow et al., 2000). Production deficiencies refer to difficulties in applying taskappropriate strategies or cognitive operations to manage a given memory task (Craik, 1983; Nyberg et al., 2003). Production deficits may reflect factors such as meta-cognitive style and motivation, which may be more amenable to cognitive intervention than the factors underlying processing deficits (Bissig \& Lustig, 2007; Dunlosky et al., 2007).

\section{This Study}

The present study is a direct extension of the memory plasticity study by Brehmer et al. (2007). Eleven months after completion of the original Brehmer et al. (2007) study, 100 of the 108 individuals who took part in the original study participated in two follow-up sessions conducted to assess maintenance of skilled memory performance. The first follow-up session assessed spontaneous maintenance of memory skill, without any renewed instruction in the mnemonic technique. In the second follow-up session, participants received mnemonic instructions prior to testing to assess maintenance after experimenter-induced reactivation of task-relevant strategies.

With the follow-up assessment, we aimed at examining whether children and adults of different ages would differ in the degree to which they were able to maintain the high levels of memory performance attained 11 months before as a result of mnemonic instruction and practice (see Figure 1). The study was guided by two expectations. First, we expected children to improve their memory performance over the 11-month time interval because the continued maturation of neural correlates of mnemonic functions (e.g., prefrontal cortex and its connectivity to mediotemporal brain areas) would allow a more effective application of the previously acquired and practiced memory strategy. Second, we expected that levels of memory performance would remain stable in younger adults, indicating the ability to maintain a formerly acquired, well-trained skill over several months.

Regarding older adults, we assumed that older adults' lower levels of performance at the end of the original experiment primarily reflected processing deficits, rather than production deficits, because instruction and practice should have reduced the influence of the latter. Given that a period of 11 months is a relatively short time for senescent changes to be revealed in task-relevant processing resources in early old age, we thus expected that older adults would show relatively few indications of decline in memory skill. 


\section{Method}

\section{Study Participants}

Twenty-three younger children (aged $10-11, M=11.3$ years), 27 older children (aged $12-13, M=13.4$ years), 23 younger adults (aged 21-26, $M=24.1$ years), and 27 older adults (aged 66-79, $M=69.3$ years) participated in the study. All participants had completed the multisession memory training described in Brehmer et al. (2007). Of the 108 participants of the original study, 6 younger adults and 2 older adults dropped out for reasons of relocation or poor health, respectively. All the children in the original study participated in the follow-up study. Each participant was paid a total of 22 euros for taking part in the two sessions of the follow-up study.

Before individuals participated in the original memory training study, we assessed their cognitive functioning using a psychometric test battery. The participants showed the expected life-span dissociation between abilities in broad fluid (memory, perceptual speed, and reasoning) and broad crystallized (verbal knowledge) domains, with an inverted $U$-shape function for fluid intelligence and a continuous age-related increase in crystallized intelligence. To measure age-related changes in cognitive functioning at followup, we applied two tasks of the original psychometric test battery. Individuals' broad fluid cognitive abilities were assessed with one marker test of perceptual speed, Digit Symbol Substitution test, and individuals' crystallized abilities with one marker test of verbal knowledge, Spot-A-Word test. Comparing the performance on these two tests from initial assessment to follow-up, we found that the general life-span trajectories of cognitive functioning were maintained over time. At the same time, changes in performance differed across the four age groups, suggesting performance improvements in children and stability in adults (see Table 1 for details).

\section{Memory Materials and Imagery Mnemonic}

As reported in Brehmer et al. (2007), episodic memory performance was assessed by cued recall of "location-word" pairs. Each

Table 1

Sample Characteristics

\begin{tabular}{|c|c|c|c|c|c|c|}
\hline \multirow[b]{2}{*}{ Participant group } & \multicolumn{2}{|c|}{$\begin{array}{c}\text { Initial } \\
\text { assessment }\end{array}$} & \multicolumn{2}{|c|}{$\begin{array}{l}\text { Follow-up } \\
\text { assessment }\end{array}$} & \multicolumn{2}{|c|}{ Paired $t$ test } \\
\hline & $M$ & $S D$ & $M$ & $S D$ & $M$ & $S D$ \\
\hline & \multicolumn{6}{|c|}{ Digital Symbol Substitution test } \\
\hline Younger children & 42.5 & 6.0 & 50.5 & 9.0 & 5.87 & $p<.5$ \\
\hline Older children & 47.0 & 6.0 & 53.0 & 7.6 & 4.83 & $p<.5$ \\
\hline Younger adults & 70.0 & 7.1 & 72.1 & 4.7 & 1.78 & $n s$ \\
\hline Older adults & 44.7 & 7.0 & 45.4 & 7.2 & 0.80 & $n s$ \\
\hline \multicolumn{7}{|c|}{ Spot-a-Word test } \\
\hline Younger children & 5.6 & 4.4 & 8.0 & 5.4 & 3.54 & $p<.5$ \\
\hline Older children & 11.0 & 5.0 & 12.0 & 5.2 & 0.87 & $n s$ \\
\hline Younger adults & 21.0 & 4.7 & 21.7 & 5.3 & 0.92 & $n s$ \\
\hline Older adults & 27.4 & 3.8 & 27.4 & 4.3 & 0.15 & $n s$ \\
\hline
\end{tabular}

Note. Perceptual speed was measured by the Digital Symbol Substitution test, and verbal knowledge was measured by the Spot-a-Word test (see Lindenberger, Mayr, \& Kliegl, 1993, for a detailed description of this test). Within each age group, paired $t$ tests were conducted to test for significant performance changes between the initial assessment and the follow-up. study list consisted of 16 location-word pairs. The same 16 generic city locations (e.g., bakery, bus stop) used in the initial memory training study were recycled as location cues in each word list. The presentation order of location cues was randomized across lists during encoding and retrieval. The to-be-recalled words were taken from the pool of 413 highly imaginable words used in Brehmer et al. (2007). Words had been selected from a larger pool with the intent to minimize age differences in word knowledge (see Brehmer, Müller, von Oertzen, \& Lindenberger, 2004).

Each session consisted of six lists. Because we sought to examine whether maintenance was moderated by memory for previously learned materials, half of the word lists were "old" (i.e., words identical to the ones used at posttest in the original study and presented at the identical location cues). The first three lists of the first follow-up session were identical to the first three lists of the posttest of the original training study (i.e., identical to-belearned words and identical word-location cue matching), while the last three word lists consisted of new words (i.e., words that had never been used before matched with the well-known location cues). In the second follow-up session, the first three word lists were identical to the last three word lists of the posttest of the original study, while the last three word lists also consisted of new words. ${ }^{1}$

In the memory training study, individuals were instructed in and trained with a specific mnemonic memory strategy (and received renewed instruction in the second follow-up session), which was a modified version of the method of loci $(\mathrm{MoL})$. In contrast to the standard MoL, the location cues were presented randomly and cued during encoding and retrieval phases throughout the experiment. This manipulation was implemented to prevent the influence of individual and age differences on the ability to accurately retrieve serial-order information from long-term memory to episodic memory (e.g., Brown, Vousden, McCormack, \& Hulme, 1999; Kausler, 1994). Furthermore, this randomized-cue approach strengthened the associative processing at the level of individual location-word pairs and thus maximized its relative contribution to successful recall (cf. Werkle-Bergner, Müller, Li, \& Lindenberger, 2006).

\section{Procedures}

In the following, the design of the present study is presented (see Table 2), including a brief summary of the original training study for completeness. However, only the posttest of the original memory training study is of relevance for the following analysis.

Original training study. The original study started with a baseline assessment in which individuals were asked to encode and recall word lists without further assistance. In the following two sessions, individuals were instructed in and practiced with the

\footnotetext{
${ }^{1}$ Due to the fact that the old words were always used in the first three lists and the new words in the last three lists of the two follow-up sessions, we could not separate the effect of stimulus material from a position effect (position of the lists within a session) by simply comparing the first three with the last three lists. In general, the performance decreases across lists within a session. Therefore, the mean of the last three lists will always be lower than the mean of the first three lists, and the effects of stimulus material and list position are always confounded. Thus, the present analysis refers to performance across lists within a session.
} 
Table 2

Outline of Study Design

\begin{tabular}{cc}
\hline \multicolumn{1}{c}{ Study phase } & \multicolumn{1}{c}{ Description } \\
\hline $\begin{array}{c}\text { Posttest session in original } \\
\text { study (Brehmer et al., 2007) }\end{array}$ & $\begin{array}{c}\text { Final session of original study, which } \\
\text { included 8-10 sessions of } \\
\text { instruction and adaptive practice. } \\
\text { First follow-up session (average } \\
\text { time lag to posttest session of } \\
\text { original study was 11 } \\
\text { months) }\end{array}$ \\
$\begin{array}{l}\text { with individually adjusted } \\
\text { encoding times (identical for each } \\
\text { individual) to the encoding times } \\
\text { used in the posttest session of the } \\
\text { original study. No mnemonic }\end{array}$ \\
$\begin{array}{l}\text { instruction given. } \\
\text { Mecond follow-up session } \\
\text { (average time lag to first } \\
\text { follow-up session was about } \\
\text { 1 week) }\end{array}$ & $\begin{array}{l}\text { assessment of memory perfor- } \\
\text { mance with individually adjusted } \\
\text { encoding times as in first follow- } \\
\text { up. }\end{array}$ \\
\hline
\end{tabular}

modified version of the MoL. The instruction emphasized that participants could form strong associations between location cues and to-be-learned words by generating interactive images. In this phase of the experiment, participants received a lot of support and encouragement to ensure that they understood the instructions and were able to utilize the mnemonic strategy (e.g., discussion of image formation and retrieval, collaborative image generation, assistance during recall, repetition and elaboration of instructions). After postinstruction assessment (assessment of the benefits of instruction on memory performance), participants accomplished 3-6 sessions of adaptive practice, in which task difficulty was individually adjusted (cf. Kliegl \& Lindenberger, 1993) until performance levels had stabilized. Task difficulty was adjusted by individually reducing the encoding time per word to maximize the likelihood that a given individual would correctly recall 10 of 16 items $(62.5 \%$ correct recall criterion) in the next list (see Brehmer et al., 2004, for details and a numerical example of the adaptive algorithm). The original training study ended with a posttest assessment in which the amount of individuals' developmental plasticity was assessed.

Posttest assessment in original study. Individuals' performance in the last session of the original study served as the reference point for the two follow-up sessions. In the posttest session, each participant worked on six lists with 16 items each. Encoding times were individually adjusted so that individuals in all age groups would approximate a performance level of $50 \%$ correctly recalled words. The time-relative criterion of correct performance differed between practice $(62.5 \%$ correct $)$ and posttest $(50 \%$ correct) due to motivational aspects (higher during practice) and considerations for special electroencephalography (EEG) analysis at posttest (which are not reported in this article).

First follow-up session. The first follow-up session measured spontaneous maintenance of the trained memory performance. For each participant, the procedure was identical to the posttest assessment in the original study. That is, participants worked on six lists of 16 location-word pairs with the same encoding times as they had been given in the posttest 11 months earlier. Participants were instructed to recall as many words as possible, without reference to any kind of strategy. The average time elapsing between the posttest session and the first follow-up session did not differ among age groups, $F(3,96)=0.11, p=.956, \eta^{2}=.003$.

Second follow-up session. The session started with a brief introduction to the mnemonic memory technique. The instruction was similar to the instruction given during the first of the two instruction sessions of the original study. Special emphasis was placed on the effectiveness of generating interactive associations between location cues and the to-be-learned words. After instruction, each participant worked on six lists of 16 items, again with the same individually adjusted encoding times. The average time elapsing between the two follow-up sessions was 6 days and did not differ between age groups, $F(3,96)=0.96, p=.417, \eta^{2}=$ .029 .

Encoding and recall phases. During encoding, location cues were presented visually (as writings) on the monitor, and the to-be-learned words were presented auditorily over headphones. First, the location cues were presented. Then the location cues were replaced by a fixation cross, and the corresponding to-belearned words were presented. Participants worked with individualized encoding times of the to-be-leaned words, which were adjusted by an adaptive algorithm during the initial memory training study. Participants started the recall phase by pressing the space bar. After the location cue was presented, a visual signal was given for the participants to start responding. To minimize the influence of individual differences in spelling ability on individual differences in episodic memory performance, we asked the participants to give their responses by entering only the first three letters of the corresponding word and to correct their responses by using the backspace key. The 16 words within each list always differed in their first three letters, and a computer program was developed that checked for letter replacements, deletions, or insertions. After recall of each list, participants were given feedback about their performance; for further details, see Brehmer et al. (2007).

Recall/time scores. Raw recall scores were influenced by encoding times, which differed across individuals and age groups but were invariant within individuals across the three occasions of primary interest in this report (i.e., posttraining session of the original study and the two follow-up sessions). Therefore, raw recall scores were not suitable for between-person and betweenage-group comparisons in levels of memory skill. To account for group differences in the ranges of encoding times needed to achieve a fixed accuracy level, we computed a recall/time score that expressed recall performance ( $c i$ ) relative to log encoding time (et; see Equation 1; for further details, see Brehmer et al., 2007). This recall/time score allows for between-person as well as between age group comparisons in the level of memory skill.

$$
\frac{\sum_{i=1}^{n} \frac{c i}{\ln (1+e t)}}{n}
$$

\section{A-Priori Contrasts of Life Span Differences in the Durability of Memory Plasticity}

We defined three orthogonal a priori contrasts, in line with the guiding hypotheses. The first contrast compared performance between the two groups of children, and the second contrast compared groups of younger and older adults. The third comparison contrasted the two groups of children with the two groups of adults 
to test whether maintenance of memory skill is greater in childhood than in adulthood. Post hoc analyses between children and younger adults were performed when both the second and the third contrast reached significance. For all analyses, the alpha level was set to $p<.05$, and effect sizes are reported as partial $\eta^{2}$. Whenever variance homogeneity assumptions were violated, GreenhouseGeisser and Huynh-Feldt adjustments were applied, with identical results unless mentioned otherwise.

\section{Results}

\section{Overview of Analyses}

We analyzed life-span differences in spontaneous maintenance and instruction-induced reactivation of skilled memory performance by comparing the two follow-up sessions with the memory performance achieved at the posttest of the original study 11 months earlier. Then, differences in memory performance across lists within the two follow-up sessions were examined to obtain a more detailed picture of maintenance effects.

Age differences in spontaneous maintenance and reactivation of skilled memory recall. Younger adults, but also older adults, maintained their levels of memory performance from the posttest of the original study to the first follow-up session (see Figure 2). Whereas younger adults did not show further improvement at the second follow-up session, $F(1,22)=.001, p>.05$, older adults improved their performance after instruction-induced reactivation, $F(1,26)=11.03, p<.05, \eta^{2}=.29$. As predicted, both younger and older children improved their memory performance across the 11-month interval, $F(1,22)=11.73, p<.05, \eta^{2}=.35 ; F(1$, 26) $=5.19, p<.05, \eta^{2}=.17$, respectively, and neither group of children gained additionally from instruction-induced reactivation in the second follow-up session, $F(1,22)=1.48, p>.05 ; F(1$, 26) $=.29, p>.05$, respectively.

Comparisons across age groups yielded a significant main effect of session, $F(2,192)=14.21, p<.5, \eta^{2}=.13$, reflecting performance changes across the three sessions. Although the main effect of age group was not interpretable with the raw numbers of recalled items as the dependent variable, the interaction effect between age group and session can be used to extract differences in age-related changes across sessions. The overall interaction effect was significant, $F(6,192)=3.49, p<.5, \eta^{2}=.10$. More specifically, the a priori contrasts showed (a) that the two child groups did not differ from each other in memory maintenance from the original posttest, $F(2,192)=1.24, p>.05$, in either the first or the second follow-up session, (b) that younger and older adults did not differ from each other in memory maintenance from the original posttest to the first follow-up session, $F(1,96)=3.22$, $p>.05$, but in their performance gains following instructioninduced reactivation (older adults profited more from instruction than younger adults, $F(1,96)=7.28, p<.05, \eta^{2}=.04$ ), and (c) that children improved their memory performance across the 11month time interval more than adults, $F(1,96)=8.58, p<.05$, $\eta^{2}=.08$, but that they did not differ from adults in terms of further memory improvements in the second follow-up session, $F(1$, 96) $=1.16, p>.05$.

Age differences in within-session change of recall accuracy across lists. To explore the reasons for the spontaneous performance improvement in children from the posttest of the original training study to the first follow-up session, we also analyzed age differences in within-session list effects. In general, participants in all age groups declined in performance over lists within a session, probably as a result of proactive interference, attentional lapses, or both. To test age differences in the amount of performance decrements, we computed within-session trend scores by subtracting the number of correctly recalled items of the current list from the number of correctly recalled items in the immediately preceding list and then summed the five difference scores for each session. Higher values on this score indicate greater performance losses in the course of a session. Two advantages of this trend score are (a) that it is statistically unrelated to the mean and (b) that it does not

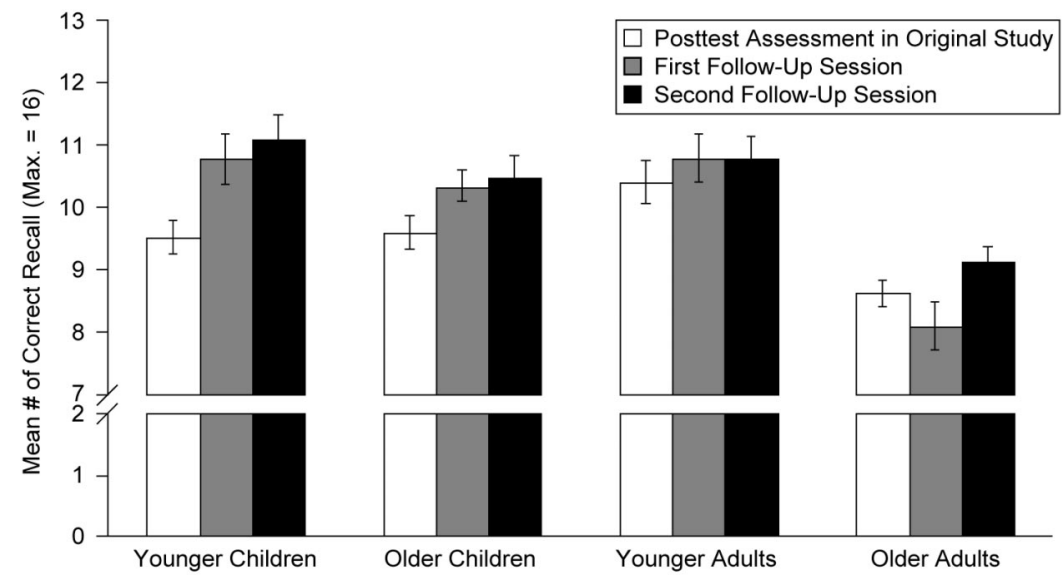

Figure 2. Average number of correctly recalled words as a function of session and age group. Recall performance is plotted separately for each age group. The white bars represent performance (number of correctly recalled words) in the posttest session of the original study (Brehmer et al., 2007), the gray bars represent performance in the first follow-up session (i.e., without mnemonic reinstruction), and the black bars represent the performance in the second follow-up session (i.e., after reinstruction in the mnemonic technique). Error bars indicate standard errors of the mean. 
mandate a specific functional form of decline (e.g., linear, exponential).

At the posttest of the original study, average within-session trend scores were $5.09,4.15,2.78$, and 3.11 for younger children, older children, younger adults, and older adults, respectively. At the first follow-up session, they were 2.17, 2.11, 2.47, and 2.63, respectively. Scores did not differ across sessions in younger adults, $t(22)=.37, p>.05$, or in older adults, $t(26)=.60, p>$ .05 , but were significantly reduced in both younger children, $t(22)=3.7, p<.05$, and older children, $t(26)=2.58, p<.05$. As shown in Figure 3, performance levels in children were similar for the posttest and the follow-up session for the first four lists but differed considerably between the two sessions for the last two lists.

Regarding the performance gradient of the children in both sessions, we should note that the results do speak against an effect of the stimulus material (e.g., that children were generally worse at recalling new words than old words that they had seen before in the posttest of the original study) because new words were already presented in List 4, but the main increase in children's performance did not occur until Lists 5 and 6 . Thus, this $4: 2$ split did not follow the 3:3 split of lists with old versus new to-be-learned words. Thus, children's increase in memory performance over the 11-month time interval was primarily due to improved performance on later lists within a session.

Age group differences in maintenance of memory skill. As mentioned before, each participant worked with individually adjusted encoding times that were fixed across lists and across the three sessions; therefore, the main effect of age group was not interpretable using the raw numbers of recalled items as dependent variable. To compare levels of memory performance across groups, we followed the procedure described by Brehmer et al. (2007) and computed recall performance over log encoding times (recall/time scores). The analysis of the combined scores showed that in addition to the main effects of measurement occasion, $F(2$ $192)=12.22, p<.5, \eta^{2}=.11$, and age group, $F(3,96)=40.66$, $p<.5, \eta^{2}=.56$, the interaction between measurement occasion and age group was also reliable, $F(6,192)=2.56, p<.5, \eta^{2}=$ 07.

For further illustration, Figure 1 displays the evolution of recall/ time scores, expressed in the pooled standard deviation units from the initial session of the original study. Clearly, the levels of recall performance attained and maintained by individuals in all age groups greatly exceeded untrained levels of performance.

(a) Younger Children

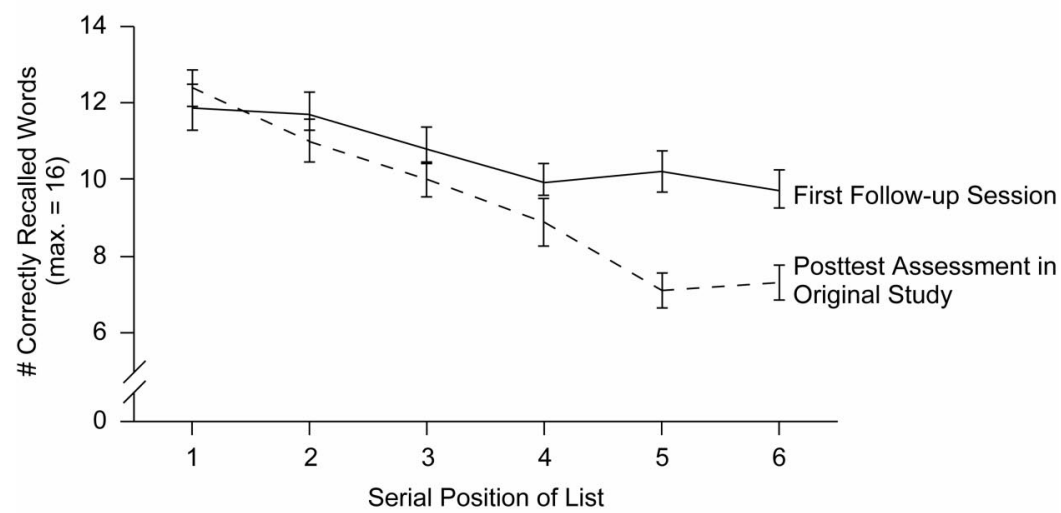

(b) Older Children

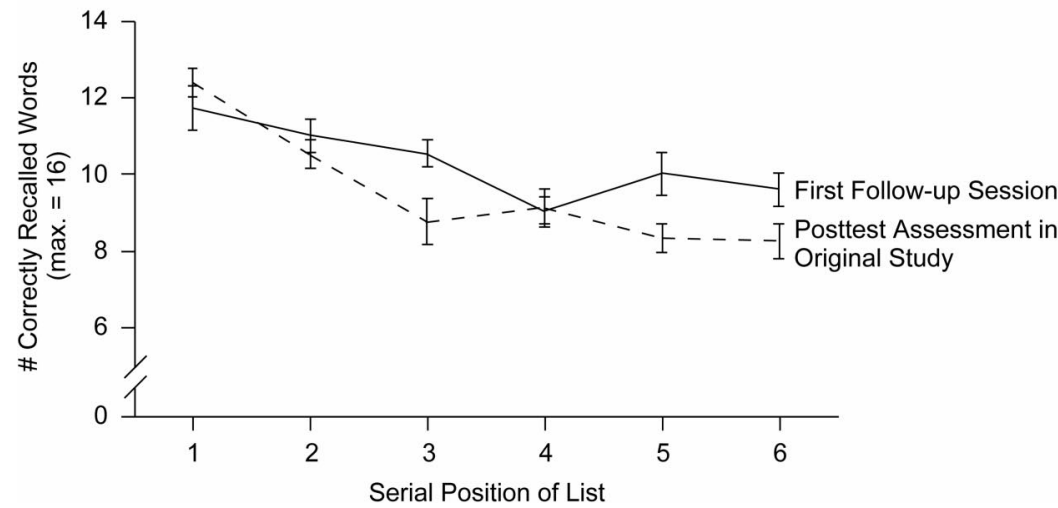

Figure 3. Number of correctly recalled words as a function of lists within sessions for (a) younger children and (b) older children. The dashed line represents the posttest session in the original study, and the black line the first session in the follow-up. The figure shows that children's increase in memory performance over the 11-month time interval was primarily due to improved performance on the two later lists within a session. Error bars indicate standard errors of the mean. 


\section{Discussion}

This study investigated life-span differences in the maintenance of skilled memory performance. Individuals in all age groups showed impressive levels of maintenance, given that there was much room for performance decrements (see Figure 1). Age groups differed in the extent to which they were able to profit from earlier learning and to which they were dependent on external context cues (renewed instruction). In accordance with findings of several maintenance studies in cognitive aging (e.g., Anschutz et al., 1987; Stigsdotter Neely \& Bäckman, 1993a, 1995), younger and older adults maintained their formerly acquired levels of skilled memory performance, showing a pattern of longitudinal performance level stability. In contrast, children further increased their performance levels in the absence of practice and showed a pattern of longitudinal growth. Whereas younger adults showed the largest recall gains in the original study, only children displayed the ability to improve performance without further practice across an 11-month period. Thus, on average, children displayed a form of long-term developmental plasticity that was absent in both younger and older adults.

\section{Improvement of Skilled Memory Performance in Children}

As can be seen in Figure 3, children's performance improvements in the first follow-up session primarily reflected a reduction in performance decline for the last two lists of a session. This finding suggests that children's memory improvements might involve maturational changes in sustained attention, inhibitory processes, or both (e.g., Adleman et al., 2002; Diamond \& Kirkham, 2005; Huttenlocher, Levine, \& Vevea, 1998; Munakata, Casey, \& Diamond, 2004; Williams et al., 1999). These changes in cognitive resources may, in turn, allow for greater stability and consistency in strategy use (Siegler, 2000). Thus, in the original study, proactive interference may have prevented children from exploiting the benefits of the mnemonic strategy to the same degree as in the follow-up session.

The Spot-a-Word and Digit Symbol Substitution tests both were administered during the original study and at follow-up. Hence, we explored whether changes in recall performance from Posttest 1 to follow-up within each of the four age groups correlated with changes in performance on these two tests. We observed a statistically reliable correlation between changes in Spot-a-Word and changes in recall performance in younger children, $r=.49, p<$ .05 . None of the other correlations was statistically reliable. The correlations observed in younger children were significantly different from the corresponding correlations observed in older children, $\mathrm{r}=-.03$, younger adults, $\mathrm{r}=-.23$, and older adults, $\mathrm{r}=$ -.04 ; for all comparisons, $p<.05$. Note that younger children showed reliable mean improvement in Spot-a-Word performance during the 11-month period between the original study and the follow-up, whereas the other groups remained stable. Thus, despite our attempts to come up with verbal materials that were equally familiar to participants of all ages, age-associated increments in verbal knowledge may have contributed to the performance gains observed in the younger children.

The present findings are reminiscent of the notion of a "sleeper" effect, introduced into the developmental intervention literature about 30 years ago (P. B. Baltes, personal communication, May,
2005; Clarke \& Clarke, 1981). The sleeper effect refers to a situation in which behavioral characteristics of the individual have consequences that are delayed. In the present case, the combination of prior learning and maturational changes led to skill improvements among children that only became apparent after the original learning environment was reinstalled.

\section{Reactivation of Skill in Older Adults}

Older adults improved their performance from the first to the second follow-up session (cf. Ball et al., 2002; Derwinger et al., 2005; Stigsdotter Neely \& Bäckman, 1993a, 1993b, 1995). They were the only age group that showed performance improvements due to renewed instruction. This finding is consistent with considerations about the role of contextual support in cognitive aging (e.g., Craik, 1983), about age deficits in context processing (e.g., Braver et al., 2001) and with the production deficit hypothesis suggested by Nyberg (2005). In line with the production deficit hypothesis, it seems that older adults do not spontaneously engage in the previously acquired and trained mnemonic strategy or that they do not apply the strategy efficiently (Kausler, 1994; Verhaeghen \& Marcoen, 1996). However, this deficit can be overcome by eliciting the strategy again through instruction. However, the overall lower episodic memory plasticity of older adults cannot be explained by production or utilization deficiencies at encoding alone but is probably also related to age-related differences in consolidation and retrieval processes (Dunlosky \& Hertzog, 1998; Dunlosky, Hertzog, \& Powell-Moman, 2005; Naveh-Benjamin, Brav, \& Levy, 2007).

In general, older adults were able to maintain their performance gains across the 11-month time interval. It should be noted, however, that the present sample of older adults was positively selected relative to the general population (see Brehmer et al., 2007). Thus, we do not know whether the ability to maintain performance gains over time can be generalized to older adults with lower memory abilities.

\section{Implications for Research on Episodic Memory Components}

At first glance, the inverted U-shaped life-span function of episodic memory efficacy seems to suggest that the mechanisms underlying changes in episodic memory performance during childhood and old age are similar. However, life-span studies on episodic memory plasticity support the proposition that these behavioral surface similarities may rely on interrelated but separable mechanisms that follow different life-span trajectories (Brehmer et al., 2007; Shing, Werkle-Bergner, Li, \& Lindenberger, in press a; Shing, Werkle-Bergner, Li, \& Lindenberger, in press b). Specifically, a recent approach to life-span changes in episodic memory distinguishes between strategic and associative components of episodic memory (Shing et al., in press b; Werkle-Bergner et al., 2006; cf. Moscovitch, 1992). The strategic component refers to selection, organization, evaluation, and elaboration processes of episodic features during encoding and retrieval. The associative component reflects binding mechanisms (i.e., formation of associative connections) between different features of a memory item, memory items, or a memory episode and its context (e.g., NavehBenjamin, 2000) that are active during encoding, consolidation, 
and retrieval. It is assumed that both components depend on different but interrelated neurofunctional circuitries (e.g., Moscovitch, 1992). The strategic component seems to depend mainly on the prefrontal cortex, while the associative component is considered to depend mostly on the mediotemporal cortex.

Because the strategic and the associative components of episodic memory closely interact in episodic memory formation and retrieval (Miller \& Cohen, 2001; Stuss \& Alexander, 2005), it is difficult to dissociate them experimentally. Life-span studies are particularly valuable in separating these two components because they are assumed to follow different life-span trajectories. The investigation of these two different ontogenetic paths may help researchers to estimate the relative contributions of strategic and associative processes to episodic memory performance (Shing et al., in press b). Recent work in child development and aging research suggests that in middle childhood, the associative component is fully functional while the strategic component is still under development (e.g., Sluzenski, Newcombe, and Kovacs, 2006). However, in older adults, the efficiency of both components declines (e.g., Chalfonte \& Johnson, 1996; Dunlosky et al., 2005; Naveh-Benjamin, 2000). The results of the original training study by Brehmer et al. (2007) were in line with these suggestions, showing that children and older adults gained a similar amount of memory improvement from mnemonic instruction (relatively higher impact of the strategic component compared with the associative component), whereas children showed greater improvement from the postinstruction to the posttraining session, which suggests greater plasticity in the associative component (see also Shing et al., in press b).

In the present study, the spontaneous skill maintenance of individuals was measured in the 11-month follow-up sessions. Individuals worked under high task demands that were identical in terms of task difficulty to those in the posttest 11 months earlier, with no explicit reference to any kind of mnemonic strategies. Therefore, in this session, the demands of an effective interaction between the strategic and the associative components were particularly high to maintain the skill levels at posttest that were acquired 11 months ago. It is interesting that children not only maintained but also improved their memory performance across the 11-month interval. They showed the highest performance potential in comparison to older adults as well as younger adults. This spontaneous improvement is probably related to the further maturation of the relevant functional brain circuitries of episodic memory (e.g., the prefrontal cortex and the mediotemporal region), supporting the strategic component of episodic memory.

\section{Limitations of the Present Study}

In interpreting the results of the present study, one should keep two major limitations in mind. First, in an attempt to secure the validity of the age comparison, we positively selected the present study sample across all age segments (see Brehmer et al., 2007). Thus, the degrees of maintenance reported here may not generalize to unbiased population samples. Second, only one specific form of memory performance was tested, with no attempts to assess near and far transfer of the skill to other aspects of episodic memory performance. In the adult developmental literature on memory training, such transfer effects, which would point to more profound changes at the level of abilities rather than at the level of specific skills, have not been observed so far (for a summary, see Baltes, Lindenberger, et al., 2006). It remains to be seen whether transfer effects, including their long-term maintenance, also differ between children and adults, reflecting qualitative differences in plasticity. We would expect that long-term transfer to other skills within the same ability domain is more likely in children than in adults, reflecting superior plasticity of cortical processing circuits (cf. Hensch, 2005).

One other issue is that our study design did not include a control group without reactivation or a control group for ruling out testretest effects. To include individuals who participated in the second follow-up session without prior renewed mnemonic instruction (no-reactivation control group) would have especially aided in the interpretations of the results obtained for older adults because they reliably improved performance from the first to the second maintenance session. We cannot specify the kind of environmental support (additional practice or reactivation of a formerly instructed and well-trained mnemonic skill) that allowed older adults to show this improvement. Regarding test-retest effects, one has to note that in the context of examining the maintenance of skilled memory performance, the individuals' follow-up performance was compared with their posttest performance in the original training study, not their initial baseline performance. Given that the performance gains of the original memory training study were enormous, the observed effects strongly exceeded any expected retest effects (see Figure 1). A control group would be of most interest in the children's groups because of their spontaneous performance improvements at the follow-up. Although there was no direct control group for the older children, their baseline and postinstruction performance in the original training study can serve as indirect control group for the younger children at follow-up assessment. The results clearly show that younger children maintained their formerly acquired and well-trained memory skill and exhibited much higher performance than older children at baseline or postinstruction in the original study (see Figure 1). Thus, the intensive adaptive training allowed all individuals to evolve their latent potential and to make use of it even after an 11-month time interval.

\section{Outlook}

The present study provides, for the first time, direct evidence of differences in the maintenance of episodic memory plasticity between children and adults. Life-span differences in maintenance skill point to interactive and dynamic relations among maturation, learning, and senescence (Lindenberger, Li, \& Bäckman, 2006). Children's longitudinal improvements in memory skill suggest that the implementation of an effective meta-cognitive strategy acquired earlier in life may have positive cascading effects on later development. Older adults' ability to maintain levels of performance attained 11 months ago confirms that the neuronal machinery required for the acquisition and maintenance of skilled memory performance is well preserved among cognitively healthy older adults. Future longitudinal life-span comparisons of behavioral plasticity should include a larger range of cognitive measures and neuronal evaluation tools such as EEG or magnetoencephalography (MEG), magnetic resonance imaging (MRI), and functional MRI (fMRI) to assess the generality and the neuronal mechanisms of life-span differences in skill maintenance. 


\section{References}

Adleman, N. E., Menon, V., Blasey, C. M., White, C. D., Warsofsky, I. S., Glover, G. H., et al. (2002). A developmental fMRI study of the Stroop color-word task. Neuroimage, 16, 61-75.

Anschutz, L., Camp, C. J., Markley, R. P., \& Kramer, J. J. (1987). Remembering mnemonics: A three-year follow-up on the effects of mnemonics training in elderly adults. Experimental Aging Research, 13, 141-143.

Bäckman, L., Nyberg, L., Lindenberger, U., Li, S.-C., \& Farde, L. (2006). The correlative triad among aging, dopamine, and cognition: Current status and future prospects. Neuroscience and Biobehavioral Reviews, 30, 791-807.

Ball, K., Berch, D., Helmers, K. F., Jobe, J. B., Leveck, M. D., Marsiske, M., et al. (2002). Effects of cognitive training interventions with older adults. Journal of the American Medical Association, 13, 2271-2281.

Baltes, P. B. (1987). Theoretical propositions of life-span developmental psychology: On the dynamics between growth and decline. Developmental Psychology, 23, 611-626.

Baltes, P. B., \& Kliegl, R. (1992). Further testing of limits of cognitive plasticity: Negative age differences in a mnemonic skill are robust. Developmental Psychology, 28, 121-125.

Baltes, P. B., Lindenberger, U., \& Staudinger, U. M. (2006). Lifespan theory in developmental psychology. In W. Damon \& R. M. Lerner (Eds.), Handbook of child psychology: Vol. 1. Theoretical models of human development (6th ed., pp. 569-664). New York: Wiley.

Baltes, P. B., Reuter-Lorenz, P. A., \& Roesler, F. (2006). Lifespan development and the brain: The perspective of biocultural co-constructivism. Cambridge, MA: Cambridge University Press.

Bialystok, E., \& Craik, F. I. M. (2006). Lifespan cognition: Mechanisms of change. Oxford, UK: Oxford University Press.

Bissig, D., \& Lustig, C. (2007). Who benefits from memory training? Psychological Science, 18, 720-726.

Bjorklund, D. F., Miller, P. H., Coyle, T. R., \& Slawinski, J. L. (1997). Instructing children to use memory strategies: Evidence of utilization deficiencies in memory training studies. Developmental Review, 17, 411-441.

Bjorklund, D. F., Ornstein, P. A., \& Haig, J. R. (1977). Developmental differences in organization and recall: Training in the use of organizational techniques. Developmental Psychology, 13, 175-183.

Bjorklund, D. F., Schneider, W., Cassel, W. S., \& Ashley, E. (1994). Training and extension of a memory strategy: Evidence for utilization deficiencies in the acquisition of an organizational strategy in high- and low-IQ children. Child Development, 65, 951-965.

Braver, T. S., Barch, D. M., Keys, B. A., Carter, C. S., Cohen, J. D., Kaye, J. A., et al. (2001). Context processing in older adults: Evidence for a theory relating cognitive control to neurobiology in healthy aging. Journal of Experimental Psychology: General, 130, 746-763.

Brehmer, Y., Li, S.-C., Müller, V., von Oertzen, T., \& Lindenberger, U. (2007). Memory plasticity across the life span: Uncovering children's latent potential. Developmental Psychology, 43, 465-478.

Brehmer, Y., Müller, V., von Oertzen, T. \& Lindenberger, U. (2004). Episodic memory in childhood and old age: The role of cortical coherence. In A. Mecklinger, H. Zimmer, \& U. Lindenberger (Eds.), Bound in memory: Insights from behavioral and neuropsychological studies (pp. 69-91). Herzogenrath, Germany: Shaker.

Brooks, J. O., III, Friedman, L., Pearman, A., Gray, C., \& Yesavage, J. A. (1999). Mnemonic training in older adults: Effect of age, length of training, and type of cognitive pretraining. International Psychogeriatrics, $11,75-84$.

Brown, G. D. A., Vousden, J. I., McCormack, T., \& Hulme, C. (1999). The development of memory for serial order: A temporal contextual distinctiveness model. International Journal of Psychology, 34, 389-402.

Cavallini, E., Pagnin, A., \& Vecchi, T. (2003). Aging and everyday memory: The beneficial effect of memory training. Archives of Gerontology and Geriatrics, 37, 241-257.

Chalfonte, B. L., \& Johnson, M. K. (1996). Feature memory and binding in young and older adults. Memory \& Cognition, 24, 403-416.

Chugani, H. T. (1994). Development of regional brain glucose metabolism in relation to behavior and plasticity. In G. Dawson \& K. W. Fischer (Eds.), Human behavior and the developing brain (pp. 153-175). New York: Guilford Press.

Clarke, A. D. B., \& Clarke, A. M. (1981). "Sleeper effects" in development: Fact or artifact? Developmental Review, 1, 344-360.

Cowan, N. (1997). The development of working memory. In N. Cowan (Ed.), The development of memory in childhood (pp. 163-199). Hove, UK: Psychology Press.

Cox, B. D. (1994). Children's use of mnemonic strategies: Variability in response to metamemory in strategic processing on a multitrial memory task: Evidence for stability in gifted cognition. Learning and Individual Differences, 10, 273-290.

Craik, F. I. M. (1983). On the transfer of information from temporary to permanent memory. Philosophical Transactions of the Royal Society of London, Series B, 302, 341-359.

Davidson, M. C., Ams, D., Anderson, L. C., \& Diamond, A. (2006). Development of cognitive control and executive functions from 4 to 13 years: Evidence from manipulations of memory, inhibition, and task switching. Neuropsychologia, 44, 2037-2078.

Derwinger, A., Stigsdotter Neely, A., \& Bäckman, L. (2005). Design your own memory strategies! Self-generated strategy training versus mnemonic training in old age: An 8-month follow-up. Neuropsychological Rehabilitation, 15, 37-54.

Diamond, A., Briand, L., Fossella, J., \& Gehlbach, L. (2004). Genetic and neurochemical modulation of prefrontal cognitive functions in children. American Journal of Psychiatry, 161, 125-132.

Diamond, A., \& Kirkham, N. (2005). Not quite as grown-up as we like to think. Psychological Science, 16, 291-297.

Dunlosky, J., Cavallini, E., Roth, H., McGuire, C. L., Vecchi, T., \& Hertzog, C. (2007). Do self-monitoring interventions improve older adult learning? Journals of Gerontology Series B: Psychological Sciences and Social Sciences, 62, 70-76.

Dunlosky, J., \& Hertzog, C. (1998). Aging and deficits in associative memory: What is the role of strategy production? Psychology and Aging $13,597-607$.

Dunlosky, J., Hertzog, C., \& Powell-Moman, A. (2005). The contribution of mediator-based deficiencies to age differences in associative learning. Developmental Psychology, 41, 389-400.

Ferrara, R. A., Brown, A. L., \& Campione, J. C. (1986). Children's learning and transfer of inductive reasoning rules: Studies of proximal development. Child Development, 57, 1087-1100.

Fry, A. F., \& Hale, S. (2000). Relationships among processing speed, working memory, and fluid intelligence in children. Biological Psychology, 54, 1-34.

Gathercole, S. E., Oickering, S. J., Ambridge, B., \& Wearing, H. (2004) The structure of working memory from 4 to 15 years of age. Developmental Psychology, 40, 177-190.

Hensch, T. K. (2005). Critical period plasticity in local cortical circuits Nature Reviews Neuroscience, 6, 877-888.

Huttenlocher, J., Levine, S., \& Vevea, J. (1998). Environmental input and cognitive growth: A study using time-period comparisons. Child Development, 69, 1012-1029.

Kausler, D. H. (1994). Learning and memory in normal aging. New York: Academic Press.

Kennedy, B. A., \& Miller, D. J. (1976). Persistent use of verbal rehearsal as a function of information about its value. Child Development, 47 $566-569$.

Kliegl, R., \& Baltes, P. B. (1987). Theory-guided analysis of mechanisms of development and aging mechanisms through testing-the-limits and 
research on expertise. In C. Schooler \& K. W. Schaie (Eds.), Cognitive functioning and social structure over the life course (pp. 95-119). Norwood: Ablex.

Kliegl, R., \& Lindenberger, U. (1993). Modeling intrusions and correct recall in episodic memory: Adult age differences in encoding of list context. Journal of Experimental Psychology: Learning, Memory, and Cognition, 19, 617-637.

Kliegl, R., Smith, J., \& Baltes, P. B. (1989). Testing-the-limits and the study of adult age differences in cognitive plasticity of a mnemonic skill. Developmental Psychology, 25, 247-256.

Kliegl, R., Smith, J., \& Baltes, P. B. (1990). On the locus and process of magnification of age differences during mnemonic training. Developmental Psychology, 26, 894-904.

Klingberg, T., Fernell, E., Oelsen, P. J., Johnson, M. H., Gustafsson, P., Dahlström, K., et al. (2005). Computerized training of working memory in children with ADHD: A randomized, controlled trial. Journal of the American Academy of Child \& Adolescent Psychiatry, 44, 177-186.

Klingberg, T., Forssberg, H., \& Westerberg, H. (2002). Training of working memory in children with ADHD. Journal of Clinical and Experimental Neuropsychology, 24, 781-791.

Kurtz, B. E., \& Borkowski, J. G. (1984). Children's metacognition: Exploring relations among knowledge, process, and motivational variables. Journal of Experimental Child Psychology, 37, 335-354.

Lange, G., \& Pierce, S. H. (1992). Memory strategy learning and maintenance in pre-school children. Developmental Psychology, 28, 453-462.

Li, S.-C. (2003). Biocultural orchestration of developmental plasticity across levels: The interplay of biology and culture in shaping the mind and behavior across the lifespan. Psychological Bulletin, 129, 171-194.

Lindenberger, U., Kliegl, R., \& Baltes, P. B. (1992). Professional expertise does not eliminate age differences in imagery-based memory performance during adulthood. Psychology and Aging, 7, 585-593.

Lindenberger, U., Li, S.-C., \& Bäckman, L. (2006). Delineating brainbehavior mappings across the lifespan: Substantive and methodological advances in developmental neuroscience. Neuroscience and Biobehavioral Reviews, 30, 713-717.

Lindenberger, U., Mayr, U., \& Kliegl, R. (1993). Speed and intelligence in old age. Psychology and Aging, 8, 207-220.

McDowd, J. M., \& Shaw, R. J. (2000). Aging and attention: A functional perspective. In F. I. M. Craik \& T. A. Salthouse (Eds.), Handbook of cognitive aging and cognition (Vol. 2, pp. 221-292). Mahwah, NJ: Erlbaum.

Miller, E. K., \& Cohen, J. D. (2001). An integrative theory of prefrontal cortex function. Annual Review of Neuroscience, 24, 167-202.

Mitchell, K. J., Johnson, M. K., Raye, C. L., \& D'Esposito, M. (2000). fMRI evidence of age-related hippocampal dysfunction in feature binding in working memory. Cognitive Brain Research, 10, 197-206.

Moscovitch, M. (1992). Memory and working-with-memory: A component process model based modules and central systems. Journal of Cognitive Neuroscience, 4, 257-267.

Munakata, Y., Casey, B. J., \& Diamond, A. (2004). Developmental cognitive neuroscience: Progress and potential. Trends in Cognitive Sciences, 8, 122-128.

Naveh-Benjamin, M. (2000). Adult age differences in memory performance: Tests of an associative deficit hypothesis. Journal of Experimental Psychology: Learning, Memory, and Cognition, 26, 1170-1187.

Naveh-Benjamin, M., Brav, T. K., \& Levy, O. (2007). The associative memory deficit of older adults: The role of strategy utilization. Psychology and Aging, 22, 202-208.

Nelson, C. A. (2002). The ontogeny of human memory: A cognitive neuroscience perspective. In M. H. Johnson, Y. Munakata, \& R. O. Gilmore (Eds.), Brain development and cognition: A reader (Vol. 2, pp. 151-178). Oxford, UK: Blackwell.

Nelson, C. A., Monk, C. S., Lin, J., Carber, L. J., Thomas, K. M., \& Truwit,
C. L. (2000). Functional neuroanatomy of spatial working memory in children. Developmental Psychology, 36, 109-116.

Nelson, C. A., Thomas, K. M., \& de Haan, M. (2006). Neural bases of cognitive development. In W. Damon \& R. M. Lerner (Eds.-in-Chief), D. Kuhn \& R. S. Siegler (Vol. Eds.), Handbook of child psychology: Vol. 2. Cognition, perception, and language (pp. 3-57). New York: Wiley. Nyberg, L. (2005). Cognitive training in healthy aging. In R. Cabeza, L. Nyberg, \& D. C. Park (Eds.), Cognitive neuroscience of aging (pp. 309-321). Oxford, UK: Oxford University Press.

Nyberg, L., Sandblom, J., Jones, S., Stigsdotter Neely, A., Petersson, K. M., Ingvar, M., et al. (2003). Neural correlates of training-related memory improvement in adulthood and aging. Proceedings of the $\mathrm{Na}$ tional Academy of Sciences of the United States of America, 100, $13728-13733$.

Raz, N., Lindenberger, U., Ghisletta, P., Rodrigue, K. M., Kennedy, K. M., \& Acker, J. D. (in press). Neuroanatomical correlates of fluid intelligence in healthy adults and persons with vascular risk factors. Cerebral Cortex.

Raz, N., Lindenberger, U., Rodrigue, K. M., Kennedy, K. M., Head, D., Williamson, A., et al. (2005). Regional brain changes in aging healthy adults: General trends, individual differences and modifiers. Cerebral Cortex, 15, 1676-1689.

Rebok, G. W., Carlson, M. C., \& Langbaum, J. B. S. (2007). Training and maintaining memory abilities in healthy older adults: Traditional and novel approaches. Journals of Gerontology Series B: Psychological Sciences and Social Sciences, 62, P53-P61.

Salthouse, T. A. (1996). The processing-speed theory of adult age differences in cognition. Psychological Review, 103, 403-428.

Schneider, W. (2000). Research on memory development: Historical trends and current themes. International Journal of Behavioral Development, 24, 407-420.

Schneider, W., \& Sodian, B. (1988). A longitudinal study of young children's memory behaviour and performance in a sort-recall task (Paper 5). Munich, Germany: Max-Planck-Institut für Psychologische Forschung.

Sheikh, J. I., Hill, R. D., \& Yesavage, J. A. (1986). Long-term efficacy of cognitive training for age-associated memory impairment: A six-month follow-up study. Developmental Neuropsychology, 2, 413-421.

Shing, Y. L., Werkle-Bergner, M., Li, S.-C., \& Lindenberger, U. (in press a). Committing memory errors with high confidence: Older adults do but children don't. Memory.

Shing, Y. L., Werkle-Bergner, M., Li, S.-C., \& Lindenberger, U. (in press b). Associative and strategic components of episodic memory: A life span dissociation. Journal of Experimental Psychology: General.

Siegler, R. S. (2000). The rebirth of children's learning. Child Development, 71, 26-35.

Siegler, R. S. (2002). Variability and infant development. Infant Behavior and Development, 25, 550-557.

Singer, T., Lindenberger, U., \& Baltes, P. B. (2003). Plasticity of memory for new learning in very old age: A story of major loss? Psychology and Aging, 18, 306-317.

Sluzenski, J., Newcombe, N., \& Kovacs, S. L. (2006). Binding, relational memory, and recall of naturalistic events: A developmental perspective. Journal of Experimental Psychology: Learning, Memory, and Cognition, 32, 89-100.

Sowell, E. R., Peterson, B. S., Thompson, P. M., Welcome, S. E., Henkenius, A. L., \& Toga, A. W. (2003). Mapping cortical change across the human life span. Nature Neuroscience, 6, 309-315.

Stigsdotter, A., \& Bäckman, L. (1989). Multifactorial memory training with older adults: How to foster maintenance of improved performance. Gerontology, 3, 260-267.

Stigsdotter Neely, A., \& Bäckman, L. (1993a). Long-term maintenance of gains from memory training in older adults: Two 3 1/2-year follow-up 
studies. Journals of Gerontology Series B: Psychological Sciences and Social Sciences, 48, P233-P237.

Stigsdotter Neely, A., \& Bäckman, L. (1993b). Maintenance of gains following multifactorial and unifactorial memory training in late adulthood. Educational Gerontology, 19, 105-117.

Stigsdotter Neely, A., \& Bäckman, L. (1995). Effects of multifactorial memory training in old age: Generalizability across tasks and individuals. Journals of Gerontology Series B: Psychological Sciences and Social Sciences, 50, P134-P140.

Stuss, D. T., \& Alexander, M. P. (2005). Does damage to the frontal lobes produce impairment in memory. Current Directions in Psychological Science, 14, 84-88.

Verhaeghen, P., \& Marcoen, A. (1996). On the mechanisms of plasticity in young and older adults after instruction in the method of loci: Evidence for an amplification model. Psychology and Aging, 11, 164-178.

Verhaeghen, P., Marcoen, A., \& Goossens, L. (1992). Improving memory performance in the aged through mnemonic training: A meta-analytic study. Psychology and Aging, 7, 242-251.

Volkow, N. D., Logan, J., Fowler, J. S., Wang, G-J., Gur, R. C., Wong, C., et al. (2000). Association between age-related decline in brain dopamine activity and impairment in frontal and cingulate metabolism. American Journal of Psychiatry, 157, 75-80.

Werkle-Bergner, M., Müller, V., Li, S.-C., \& Lindenberger, U. (2006). Cortical EEG correlates of successful memory encoding: Implications for lifespan comparisons. Neuroscience and Biobehavioral Reviews, 30 , $839-854$.

Williams, B. R., Ponesse, J. S., Schachar, R. J., Logan, G. D., \& Tannock, R. (1999). Development of inhibitory control across the life span. Developmental Psychology, 35, 205-213.

Willis, S. L., Tennsteadt, S. L., Marsiske, M., Ball, K., Elias, J., Koepke, K., et al. (2006). Long-term effects of cognitive training on everyday functional outcomes in older adults. Journal of American Medical Association, 296, 2805-2814.

Yesavage, J. A., \& Rose, T. L. (1984). Semantic elaboration and the method of loci: A new trip for older learners. Experimental Aging Research, 10, 155-159.

Received August 7, 2007

Revision received March 4, 2008

Accepted March 17, 2008

\section{ORDER FORM}

Start my 2008 subscription to Psychology and Aging ISSN: 0882-7974

\section{\$67.00, APA Member/Affiliate \$144.00, IndividuAL NoNMEMBER \$425.00, InstiTution In DC add $5.75 \%$ / In MD add 6\% sales tax Total Amount Enclosed}

Check enclosed (make payable to APA) Charge my: OVISA $\bigcirc$ MasterCard Cardholder Name Card No. Exp. Date

BILLING ADDRESS

Street

City $\_$State _ Zip
Daytime Phone _
E-mail

MAIL TO:

Name

Address

City State Zip

APA Member \#
American Express the first issue. Call for international subscription rates.

American Psychological Association

Subscriptions

Washington, DC 20002-4242

AMERICAN PSYCHOLOGICAL ASSOCIATION
Or call 800-374-2721, fax 202-336-5568

TDD/TTY 202-336-6123.

For subscription information, e-mail: subscriptions@apa.org 